\title{
Virtual Car Information in Real Spaces Right in Your Face: Assessing the System Acceptance of Head-Up Display: An Abstract
}

\author{
Gerald-Alexander Beese, Steffen Schmidt, and Klaus-Peter Wiedmann
}

\begin{abstract}
As automotive industry and automobiles are subject to incremental changes, customer's evaluation of passenger vehicles also changes. Indeed, classic criteria such as engine performance have been paramount in consumer's buying decision processes for decades, but additional technical systems and features such as advanced driver-assistance systems (ADAS) gain importance. With regard to emerging vehicle system features such as ADAS, the main challenge for a long-term and broad product demand is consumer's acceptance. Against that background, the current work focusses on the evaluation of the technology acceptance of a so-called head-up display (HUD). Within a first step, a web study (including a real driving situation video) was performed to check the general suitability of a theoretically derived advanced system acceptance model based on literature review considering acceptance measures and frameworks. Overall, the empirical evaluation of the introduced system acceptance measurement model confirmed a high level of explaining and predictive quality. Specifically, usefulness, ease of use and society were revealed as key drivers of system acceptance for positive product performance in the current study. However, limitations regarding study design, sample and procedure require further research to gain more insights into human-machine interactions related to system acceptance in an automotive context.
\end{abstract}

\section{G.-A. Beese ( $\square)$}

KTI, Balzheim, Germany

e-mail: gbeese@k-t-i.de

S. Schmidt $\cdot$ K.-P. Wiedmann

Leibniz University of Hannover, Hannover, Germany

e-mail: schmidt@m2.uni-hannover.de; wiedmann@m2.uni-hannover.de 